\title{
Role of HTLV-1 Tax and HBZ in the Pathogenesis of HAM/TSP
}

\author{
Yoshimi Enose-Akahata, Ashley Vellucci and Steven Jacobson* \\ Viral Immunology Section, Division of Neuroimmunology and Neurovirology, National Institute of Neurological Disorders and \\ Stroke, National Institutes of Health, Bethesda, MD, United States
}

\section{OPEN ACCESS}

Edited by:

Umberto Bertazzoni,

University of Verona, Italy

Reviewed by:

Yorifumi Satou,

Kumamoto University, Japan

Masao Matsuoka

Kyoto University, Japan

*Correspondence:

Steven Jacobson

jacobsons@ninds.nih.gov

Specialty section:

This article was submitted to

Virology,

a section of the journal

Frontiers in Microbiology

Received: 17 October 2017 Accepted: 11 December 2017 Published: 21 December 2017

Citation:

Enose-Akahata Y, Vellucci A and Jacobson S (2017) Role of HTLV-1

Tax and HBZ in the Pathogenesis of HAM/TSP.

Front. Microbiol. 8:2563. doi: 10.3389/fmicb.2017.02563
Human T cell lymphotropic virus type 1 (HTLV-1) infection can lead to development of adult $\mathrm{T}$ cell leukemia/lymphoma (ATL) or HTLV-1-associated myelopathy/tropical spastic paraparesis (HAM/TSP) in a subset of infected subjects. Understanding the interaction between host and HTLV-1 and the molecular mechanisms associated with disease pathogenesis is critical for development efficient therapies. Two HTLV-1 genes, tax and HTLV-1 basic leucine zipper factor (HBZ), have been demonstrated to play important roles in HTLV-1 infectivity and the growth and survival of leukemic cells. Increased HTLV-1 Tax expression induces the expression of various cellular genes such as IL-2 and $\mathrm{IL}-15$, which directly contributes to lymphocyte activation and immunopathogenesis in HAM/TSP patients. However, little is known about the molecular and cellular mechanism of HBZ in development of HAM/TSP. It has been reported that HBZ mRNA expression was detected in HAM/TSP patients higher than in asymptomatic carriers and correlated with proviral load and disease severity. Unlike HTLV-1 tax, HBZ escapes efficient antiviral immune responses and therefore these reactivities are difficult to detect. Thus, it is important to focus on understanding the function and the role of HTLV-1 tax and HBZ in disease development of HAM/TSP and discuss the potential use of these HTLV-1 viral gene products as biomarkers and therapeutic targets for HAM/TSP.

\section{Keywords: HTLV-1, HAM/TSP, Tax, HBZ, neuroinflammatory disease}

\section{INTRODUCTION}

Human T lymphotropic virus type 1 (HTLV-1) is the first human retrovirus discovered belonging to the deltaretrovirus family and is thought to infect approximately 10-20 million people worldwide (Poiesz et al., 1980; de The and Bomford, 1993). Several highly endemic areas for HTLV-1 are known in the world such as southern part of Japan, the Caribbean, North and South America, Central and West Africa, and foci in Middle East, Australia and Melanesia (Gessain and Cassar, 2012). HTLV-1 has been demonstrated to be the etiological agent of an aggressive mature $\mathrm{T}$ cell malignancy termed adult $\mathrm{T}$ cell leukemia (ATL) (Uchiyama, 1988) and a chronic, progressive neurological disease termed HTLV-1-associated myelopathy/tropic spastic paraparesis (HAM/TSP) (Gessain et al., 1985; Osame et al., 1986). Although the majority of infected individuals are asymptomatic carriers of the virus, approximately $0.25-3.8 \%$ of infected individuals develop HAM/TSP. HAM/TSP is clinically characterized by progressive lower extremity weakness, spasticity, and bladder/bowel sphincter dysfunction (Umehara et al., 1993). The disease development of HAM/TSP mainly occurs in adults, with a mean age at onset of 40-50 years, which is more common in women than in men (Yamano and Sato, 2012). The 
disease usually progresses slowly without remission, but the clinical course and rate of progression may vary greatly among patients (Yamano and Sato, 2012). HAM/TSP is also characterized by perivascular inflammatory infiltrates in the brain and spinal cord (Umehara et al., 1993; Aye et al., 2000). In early stages of HAM/TSP, infiltrating $\mathrm{CD}^{+}$and $\mathrm{CD}^{+}$lymphocytes are present in the inflammatory lesions in the spinal cord while $\mathrm{CD}^{+} \mathrm{T}$ cells are predominantly detected in the chronic inflammatory lesions of patients with longer duration of disease (Umehara et al., 1993). The spinal cord is associated with a chronic inflammatory process with marked parenchymal exudation of inflammatory cells in both the gray and white matter, initially causing lower thoracic cord atrophy with extensive lateral and posterior column involvement (Iwasaki, 1990). As the disease progresses, axonal loss and degeneration in the form of myelin pallor is severe in the white matter and increases throughout the entire cord (Iwasaki, 1990). Recent studies of measuring spinal cord cross-sectional areas in HAM/TSP patients by magnetic resonance imaging (MRI) revealed that HAM/TSP patients had more atrophic cords compared to ACs and healthy normal donors, which was associated with disease duration (Liu et al., 2014; Azodi et al., 2017). In HAM/TSP patients who present with rapid progression, spinal cord atrophy has been demonstrated to begin in the thoracic cord and progress to the cervical cord (Azodi et al., 2017). A higher HTLV-1 proviral load (PVL) is frequently observed in the blood and the cells from cerebrospinal fluid (CSF) of HAM/TSP patients than ACs (Nagai et al., 2001b). High levels of antibodies against HTLV-1 antigens are present in blood and CSF (Gessain et al., 1985; Osame et al., 1986). Intrathecal HTLV-1-specific antibody production provides additional data to support the diagnosis of HAM/TSP. Thus, chronically activated immune responses against HTLV-1 and infiltration of inflammatory cells including HTLV-1 infected cells into the central nervous system (CNS) have been suggested to underlie the pathogenesis of HAM/TSP.

Like other retroviruses, the HTLV-1 proviral genome has structural genes, gag, pol, and env flanked by long terminal repeat at both ends. HTLV-1 genome also contains a $p X$ region between env and $3^{\prime}$ LTR encoded several accessory genes including tax, rex, p12, p21, p30, p13 and HTLV-1 basic leucine zipper factor (HBZ) (Matsuoka and Jeang, 2007). The viral genes are transcribed from the $5^{\prime}$ LTR, but only $H B Z$ encoded on the minus strand of the provirus is transcribed from the $3^{\prime}$ LTR. HTLV-1 expresses a transcriptional trans-activator protein, Tax, which induce the expression of a various cellular genes. Increased expressions of critical immune mediators directly contribute to cell activation and proliferation observed in HAM/TSP patients, suggesting that chronically activated immune responses underlie the pathogenesis of this disorder (Matsuura et al., 2010). There is also increasing evidence that $\mathrm{HBZ}$ also plays a critical part in inflammation and pathogenesis of HAM/TSP. In this review, we discuss the understanding of the function and the role of HTLV-1 Tax and HBZ in disease development of HAM/TSP and the potential use of these HTLV-1 viral gene products as biomarkers and therapeutic targets for HAM/TSP.

\section{HTLV-1 INFECTION AND HAM/TSP}

HTLV-1 causes a persistent infection in humans and replicates mainly through clonal expansion of the infected cells rather than cell-free virus infection. HTLV-1 PVLs are significantly elevated in HAM/TSP patients, compared to ACs, and is strongly correlated with disease pathogenesis of HAM/TSP (Nagai et al., 1998). Higher PVLs are detected in CSF than in peripheral blood mononuclear cells (PBMCs) of HAM/TSP patients (Nagai et al., 2001b; Araya et al., 2014; Brunetto et al., 2014). In addition, PVL was significantly higher in CSF of HAM/TSP patients than in ACs and HTLV-1-infected subjects with other neurologic diseases (Puccioni-Sohler et al., 2007). HTLV-1 can infect a wide range of human cell types including $\mathrm{T}$ cells, monocytes, macrophages and dendritic cells (Hoffman et al., 1992; Koralnik et al., 1992; Koyanagi et al., 1993; Makino et al., 1999; Hanon et al., 2000c; Enose-Akahata et al., 2008). HTLV-1 provirus is predominantly detected in $\mathrm{CD}^{+}{ }^{+} \mathrm{T}$ cells in vivo (Richardson et al., 1990) and has been associated with leukemogenesis and reduced regulatory function of $\mathrm{CD}^{+} \mathrm{T}$ cells (Uchiyama, 1988; Yamano et al., 2005). In HAM/TSP patients, $\mathrm{CD} 4{ }^{+} \mathrm{CD} 25^{+} \mathrm{T}$ cells are the main reservoir for HTLV-1 (Yamano et al., 2004). Further studies revealed that high HTLV-1 PVL was detected in $\mathrm{CD} 4{ }^{+} \mathrm{CD} 25^{+} \mathrm{CCR} 4{ }^{+} \mathrm{T}$ cells and the frequency of IFN- $\gamma$-producing $\mathrm{CD} 4{ }^{+} \mathrm{CD} 25^{+} \mathrm{CCR} 4{ }^{+} \mathrm{T}$ cells was dramatically increased in HAM/TSP patients, which was found to be correlated with disease activity and severity (Yamano et al., 2009; Araya et al., 2014). In addition, it has been demonstrated that abundant $\mathrm{CD} 4{ }^{+} \mathrm{CCR} 4^{+} \mathrm{T}$ cells which coexpressed the Th1 marker CXCR3 and produced T-bet and IFN- $\gamma$ were present in CSF and spinal cord lesions of HAM/TSP patients (Araya et al., 2014). High CSF PVLs is a strong biomarker of HAM/TSP and HTLV-1-infected cells recruited into the CNS may alter the inflammatory milieu in the CNS of HAM/TSP patients.

HTLV-1 PVL varies widely among HTLV-1-infected subjects, but the PVL remains relatively stable within each subject. The HTLV-1 genome sequence is also stable within and between infected individuals. Integration of HTLV-1 was found to favor genes, transcriptional start sites, and CpG islands (Doi et al., 2005; Derse et al., 2007). Comparison of proviral integration sites between HTLV-1-infected subjects demonstrated that HTLV-1 integration might be more frequent in transcriptionally active areas of the genome in HAM/TSP patients than in ACs and that frequent integration into transcriptionally active area of the genome was associated with an increased rate of Tax expression (Meekings et al., 2008). Moreover, a larger number of unique insertion sites, but not a difference of clonality, was detected in HAM/TSP patients than in ACs (Gillet et al., 2011). Interestingly, the majority of spontaneous Tax expressing cells corresponded to the large number of low abundance clones, rather than a small number of high abundance clones (Melamed et al., 2013), suggesting that clonal expansion of infected cells might be controlled by host immune response to Tax or by other viral factor such as HBZ in HAM/TSP patients. These reports demonstrated that cells with HTLV-1 provirus integrated near transcriptionally active areas could establish and expand more frequently in HAM/TSP patients, which would influence 
expression of HTLV-1 gene products and further contribute to the development and pathogenesis of HAM/TSP.

\section{MOLECULAR PATHOGENESIS OF TAX IN HAM/TSP}

Tax is a transforming and transactivating protein of HTLV-1 and induces the expression of a variety of cellular genes by activation of the NF-KB and CREB/ATF pathways (Matsuoka and Jeang, 2011). HAM/TSP patients showed the spontaneous increase of tax mRNA and Tax protein expression in PBMCs after ex vivo culture without any exogenous stimulators that peaks at 12-24 h (Hanon et al., 2000a; Yamano et al., 2002). The expression of tax mRNA was significantly higher in HAM/TSP patients than in ACs (Yamano et al., 2002). Tax is prominently associated with dysregulation in immune cells of HAM/TSP patients, underlying many of the characteristic immune abnormalities.

\section{Regulatory CD4 ${ }^{+} \mathrm{T}$ Cells (Tregs)}

In HAM/TSP patients, $\mathrm{CD} 4^{+} \mathrm{CD} 25^{+} \mathrm{T}$ cells contain high frequency of HTLV-1 proviral DNA, express HTLV-1 tax mRNA at significantly higher levels than in $\mathrm{CD} 4{ }^{+} \mathrm{CD} 25^{-}$cells and induces various cytokines including IFN- $\gamma$ (Yamano et al., 2004, 2009). $\mathrm{CD} 4{ }^{+} \mathrm{CD} 25^{+} \mathrm{T}$ cells, termed Tregs, that constitutively express CD25 (the IL-2 receptor $\alpha$ chain) and are engaged in the maintenance of immunologic self-tolerance by suppressing the activation and expansion of self-reactive lymphocytes that may cause autoimmune diseases (Sakaguchi et al., 2001). Although $\mathrm{CD} 4^{+} \mathrm{CD} 25^{+} \mathrm{T}$ cells have an important role in suppression of $\mathrm{T}$ cell activation both in vivo and in vitro, HTLV-1-infected $\mathrm{CD} 4{ }^{+} \mathrm{CD} 25^{+} \mathrm{T}$ cells were not functionally suppressive but rather were shown to stimulate the proliferation of HTLV-1 Tax-specific $\mathrm{CD}^{+} \mathrm{T}$ cells (Yamano et al., 2004). In HAM/TSP patients, the forkhead box P3 (FoxP3), which is critical for the function of Tregs, was decreased in $\mathrm{CD} 4^{+} \mathrm{CD} 25^{+} \mathrm{T}$ cells (Yamano et al., 2005). When Tax was transduced in $\mathrm{CD} 4^{+} \mathrm{CD} 25^{+} \mathrm{T}$ cells isolated from healthy volunteers, foxp 3 mRNA expression as well as regulatory function of the $\mathrm{CD} 4^{+} \mathrm{CD} 25^{+} \mathrm{T}$ cells was inhibited (Yamano et al., 2005).

Other immune molecules related to Tregs were also dysregulated by Tax in HAM/TSP patients. The pleiotropic cytokine, transforming growth factor- $\beta$ (TGF- $\beta$ ), play critical roles in suppressing the immune response, such as inhibition of inflammatory responses and promotion of Treg generation and function (Wan and Flavell, 2007). Dysregulation of TGF- $\beta$ signaling has been reported in HAM/TSP patients, due to inhibition of TGF- $\beta$ RII and Smad7 expression by Tax (Grant et al., 2008). OX40 is a member of the TNF costimulatory receptor family and is expressed on activated $\mathrm{T}$ cells. Costimulatory signals from OX40 promote proliferation and survival of effector and memory $\mathrm{T}$ cell population and also suppresses the differentiation and activity of Tregs (Croft et al., 2009). Tax has been demonstrated to transactivate OX40 (Higashimura et al., 1996). In HAM/TSP patients, OX40 was expressed in $\mathrm{CD}^{+} \mathrm{T}$ cells depending on Tax expression after the culture (Saito et al., 2013). Higher levels of soluble
OX40 was detected in the CSF of HAM/TSP patients with rapid progression, and OX40 was overexpressed in spinal cord infiltrating mononuclear cells in a clinically progressive HAM/TSP patient with a short duration of illness (Saito et al., 2013). Thus, decreased Treg function may cause immune dysregulation in HAM/TSP patients.

\section{The Common $\gamma$ Chain Family of Cytokines}

The common $\gamma$ chain family of cytokines including IL-2, IL-7, IL-9, IL-15, and IL-21 play an important role in lymphocyte proliferation, survival and function during immune responses and homeostasis. Tax has been shown to transactivate a number of the common $\gamma$ chain family of cytokines and the receptors, such as IL-2/IL-2R, IL-9, IL-15/IL-15R, and IL-21/IL-21R (Cross et al., 1987; Siekevitz et al., 1987; Azimi et al., 1998; Mariner et al., 2001; Mizuguchi et al., 2009). One of the most striking features of the cellular immune response in HAM/TSP patients is the increased numbers of memory and/or effector $\mathrm{CD} 8^{+}$ $\mathrm{T}$ cells and also HTLV-1 Tax-specific cytotoxic CD8 ${ }^{+} \mathrm{T}$ cells (Jacobson et al., 1990; Nagai et al., 2001a). Since both IL-2 and IL-15 induce the proliferation and increase the cytolytic activity of $\mathrm{NK}$ and $\mathrm{CD}^{+} \mathrm{T}$ cells, it has been suggested that IL2/IL-2R and IL-15/IL-15R autocrine loop may contribute to the pathogenesis of HAM/TSP (Azimi et al., 1999). In particular, IL-15 is critical for the development of NK cells and antigenspecific memory $\mathrm{CD} 8^{+} \mathrm{T}$ cells and is well characterized for its role in maintaining memory pools of $\mathrm{CD} 8^{+} \mathrm{T}$ cells. In HAM/TSP patients, $I L-15$ mRNA level is up-regulated in non-T cells isolated from HAM/TSP patients and DC treated with HTLV-1 Tax protein in vitro (Azimi et al., 1999; Ahuja et al., 2006). IL-15 expression was also rapidly enhanced on the surface of $\mathrm{CD} 14^{+}$ cells in HAM/TSP patients after the PBMC culture, more than those in ACs (Enose-Akahata et al., 2008). In addition, high expression of IL-15R $\alpha$ has been reported in HTLV-1 Tax-specific $\mathrm{CD}^{+} \mathrm{T}$ cells, compared with CMV pp65-specific CD8 ${ }^{+} \mathrm{T}$ cells (Azimi et al., 2001). IL-15 stimulated HTLV-1 Tax-specific CD8 ${ }^{+}$ $\mathrm{T}$ cells, but not CMV pp65-specific $\mathrm{CD}^{+} \mathrm{T}$ cells, to induce degranulation and IFN- $\gamma$ expression (Enose-Akahata et al., 2008). Thus, the increase of the common g chain family of cytokines and receptors in HAM/TSP patients may be involved in increased proliferation and enhanced cytolytic activity and inflammatory cytokine production of HTLV-1-specific $\mathrm{CD}^{+} \mathrm{T}$ cells.

Increased levels of cytokines and the receptors driven by Tax further lead to upregulated protein expression and activated signaling cascades, such as JAK/STAT (Waldmann, 2015). IL-2/IL-15 binding to the $\beta / \gamma$ chain complex results in heterodimerization of their cytoplasmic domains with activation of the Janus family tyrosine kinases, JAK1 and JAK3 (in association with $\beta$ and $\gamma$ chain, respectively). Activated JAK1 and JAK3 then phosphorylate signal transducer and activator of transcription proteins STAT3 and STAT5, respectively, to mediate IL-2 and IL-15 effects in immune cells (Waldmann, 2015). HAM/TSP patients showed increased STAT5 phosphorylation in $\mathrm{T}$ cells, which was inhibited by the blockade of IL-2R $\alpha$ and IL-2/IL-15R $\beta$ (Oh et al., 2011). 
These reports demonstrated that continuous stimulation driven through HTLV-1 Tax may be associated with the pathogenesis of HAM/TSP.

\section{The Blood-Brain Barrier (BBB)}

The CNS is normally protected from infectious agents by a physiological structure called the blood-brain barrier (BBB), which consists primarily of a continuous endothelium with tight junctions. HAM/TSP develops upon infiltration of HTLV-1infected lymphocytes into the CNS, mostly within the thoracic spinal cord. The tight junctions of the BBB endothelium in HAM/TSP patients are locally disorganized (Afonso et al., 2007, 2008). Matrix metalloproteinase (MMP) is known as a proteolytic enzyme, which is involved in degradation of many different components of extracellular matrix and is critical role in migration of leukocytes and damage of the BBB. It has been reported that high level of MMP-2 and MMP9 was detected in the CSF and in infiltrating mononuclear cells of HAM/TSP patients, suggesting that MMP-2 and MMP-9 may cause disruption of BBB in HAM/TSP patients (Umehara et al., 1998). Later, MMP-9, but not MMP-2, was reported to be transactivated by Tax in HTLV-1-infected T cells (Mori et al., 2002). HTLV-1 infection has been also detected in astrocytes which interact with endothelial cells to form the BBB and may potentially also function as antigenpresenting cells (Lehky et al., 1995; Mendez et al., 1997). The expression of Tax in primary human astrocytomas and oligodendrogliomas resulted in robust induction of IL- $1 \alpha$, IL-1 $\beta$, TNF- $\alpha$, TNF- $\beta$, and IL- 6 expression (Banerjee et al., 2007). These results suggested that increased inflammatory responses may cause disruption of $\mathrm{BBB}$ and the alteration of the $\mathrm{BBB}$ integrity may allow $\mathrm{T}$ cells to transmigrate into the CNS, resulting in neuroinflammation of HTLV-1-infected subjects.

Recruitment and extravasation of $\mathrm{T}$ cells through the $\mathrm{BBB}$ are favored by adhesion molecule-mediated interactions of circulating $\mathrm{T}$ cells with endothelial cells. Tax has been demonstrated to regulate cell adhesion molecules, such as intercellular adhesion molecule-1 (ICAM-1), vascular cell adhesion molecule 1 (VCAM-1) and cell adhesion molecule 1 (CADM1/TSLC1) (Valentin et al., 1997; Nejmeddine et al., 2009; Manivannan et al., 2016). Activated leukocyte cell adhesion molecule (ALCAM/CD166), a member of the immunoglobulin superfamily, is overexpressed on the surface of HTLV-1-infected lymphocytes, both in chronically infected cell lines and in primary $\mathrm{CD} 4^{+} \mathrm{CD} 25^{+} \mathrm{T}$ cells from HAM/TSP patients (Curis et al., 2016). ALCAM expression was enhanced by Tax through the activation of the canonical NF- $\mathrm{BB}$ pathway (Curis et al., 2016). These results demonstrated that increase of ALCAM expression might facilitate the migration of HTLV-1-infected lymphocytes across the BBB endothelium.

\section{Tax in CSF of HAM/TSP Patients}

Although tax mRNA and Tax protein are rarely or undetectable directly in fresh uncultured PBMCs of HAM/TSP patients, it has been reported that HTLV-1 tax mRNA was detected in cells of spinal cord and cerebellar sections, and HTLV-1 Tax protein could be also detected in CSF cells of HAM/TSP patients (Lehky et al., 1995; Moritoyo et al., 1999; Cartier and Ramirez, 2005). The increased expression of HTLV-1 Tax protein in the CSF cells was more frequent in HAM/TSP patients with shorter duration of illness (Cartier and Ramirez, 2005). The presence of Tax protein in CSF might cause direct cell damage and loss in the CNS or immune cells to activate and generate Tax-specific immune responses in HAM/TSP patients. Axonal degeneration in HAM/TSP patients occurs without HTLV-1 infection of neurons, suggesting that secreted Tax protein might be involved. Tax from culture media of MT-2 and PBMCs of HAM/TSP patients caused retraction of differentiated human neuroblastoma cells (Maldonado et al., 2011; Medina et al., 2014). Tax expression also sensitized primary astrocytomas to apoptosis (Banerjee et al., 2007). These observations suggest that the chronic Tax secretion from infected cells could be sufficient for producing a neurotoxic effect on the long axons of corticospinal tracts involved in progressive neurological disease. Recent increasing evidences revealed that extracellular vesicles called exosomes play critical roles in viral pathogenesis and control of host immune responses to viral infection that deliver these microvesicles that contain host and viral components, including proteins, mRNA, and microRNA (Anderson et al., 2016). HTLV-1 has been shown to incorporate viral products into shed exosomes. Jaworski et al. (2014) found exosomes derived from HTLV-1-infected cells to contain Tax protein and proinflammatory mediators as well as viral mRNA transcripts, including Tax, HBZ, and Env. Once viral proteins or viral mRNAs enter or are released from exosomes in the CNS, these viral products might be able to stimulate or damage resident cells in the CNS or sensitize uninfected target cells for lysis by HTLV-1-specific CD8 ${ }^{+} \mathrm{T}$ cells. These new findings suggest that incorporation of viral proteins and mRNAs into exosomes or alteration of host contents of immune cell derived exosomes may represent a mechanism by which viral antigens could be transported to the CNS and be associated with axonal degeneration and virus-specific immune responses in HAM/TSP.

\section{MOLECULAR PATHOGENESIS OF HBZ IN HAM/TSP}

HBZ encoded by the minus strand of the HTLV-1 proviral genome has been identified (Gaudray et al., 2002). While about $60 \%$ of ATL patients do not express the tax gene transcript in freshly isolated leukemic cells (Takeda et al., 2004), HBZ mRNA is ubiquitously expressed in HTLV-1-infected cells, ATL cells and PBMC of HTLV-1-infected individuals and promotes the growth and survival of the leukemic cells (Satou et al., 2006; Usui et al., 2008). HBZ interacts with CREB/ATF pathway, suppress Tax-mediated viral transcription, and selectively inhibits the classical NF- $\mathrm{KB}$ pathway (Matsuoka and Jeang, 2011). Previous in vivo studies also demonstrated that HBZ expression enhanced HTLV-1 infectivity, T cell proliferation and lymphoma (Arnold et al., 2006, 2008; Satou et al., 2011). While it has been reported that HBZ plays a crucial role in 
HTLV-1 infectivity and the generation and maintenance of the oncogenic process, there is less information about the role of $\mathrm{HBZ}$ on the molecular and cellular mechanisms leading to HAM/TSP.

\section{Localization of HBZ}

The expression of $H B Z$ mRNA was detected in PBMCs of HAM/TSP patients, which was significantly lower than in ATL patients but higher than in AC (Saito et al., 2009). Intriguingly, HBZ mRNA expression was correlated with PVL and disease severity in HAM/TSP patients (Saito et al., 2009). It remains unclear how expression of Tax (the plus strand transcription is minimized) and HBZ (constitutively expressed from the minus strand) is regulated in HTLV-1-infected cells, but there is increasing evidence that $\mathrm{HBZ}$ expression is detected in a different pattern or subset of $\mathrm{CD}^{+} \mathrm{T}$ cells from Taxexpressing $\mathrm{CD}^{+} \mathrm{T}$ cells. It has been demonstrated that high frequency of $\mathrm{CD} 39^{+} \mathrm{CD} 4{ }^{+} \mathrm{T}$ cells regardless of $\mathrm{CD} 25$ expression were detected in HAM/TSP patients compared to AC (Leal et al., 2013). When Tax and HBZ expression was examined in $\mathrm{CD}^{+} \mathrm{T}$ cells expressing CD25 and CD39 of HAM/TSP patients, $H B Z$ mRNA expression was significantly correlated with $\mathrm{CD} 39^{+} \mathrm{CD} 4^{+} \mathrm{T}$ cells while Tax expression was restricted to $\mathrm{CD} 25$-expressing $\mathrm{CD}^{+} \mathrm{T}$ cells regardless of CD39 expression (Leal et al., 2013). Moreover, a recent study using single molecule RNA fluorescent in situ hybridization targeted to the transcripts of tax or $H B Z$ genes revealed that tax mRNA expression was enhanced in the absence of $H B Z$ mRNA in patient-derived $\mathrm{HTLV}-1^{+} \mathrm{T}$ cell clones while $H B Z$ mRNA expression was increased in cells with high tax mRNA expression (Billman et al., 2017). In addition, it has been demonstrated that at the single cell level, $H B Z$ mRNA was expressed at much lower level, detected in more uniformly across cells compared to tax mRNA, and was not expressed in all $\mathrm{T}$ cell clones (Billman et al., 2017). These studies suggested that HBZ expression might be compartmentalized or cooperate with Tax expression in HTLV-1-infected T cells. A recent study demonstrated that CTCF, a zinc-finger protein and a key regulator of chromatin structure and function, bound to HTLV-1 and formed loops between proviral and host genes to regulate HTLV-1 proviral transcription and RNA splicing (Satou et al., 2016). Further molecular virological studies would be necessary to understand how the pattern of proviral transcription and latency is regulated in HTLV-1infected individuals.

Unlike $H B Z$ mRNA, HBZ protein was rarely detected in HAM/TSP patients (Shiohama et al., 2016). Previously, higher nuclear retention of $\mathrm{HBZ}$ mRNA and localization of $\mathrm{HBZ}$ in the nucleus have been demonstrated (Hivin et al., 2005; Rende et al., 2011), suggesting that HTLV-1 might favor viral persistence by reducing $\mathrm{HBZ}$ translation to escape the infected cells from HBZ-specific immune responses. However, HBZ protein has been recently reported to be localized in the cytoplasm of $\mathrm{T}$ cells depending on the expression of THEMIS (thymocyte-expressed molecule involved in selection), a recently identified $\mathrm{T}$ lineage-restricted protein (Kinosada et al., 2017). HBZ interfered complex formation of THEMIS with Grb2 and
SHP-2, which resulted in inhibition of suppressive function of coinhibitory receptors, such as $\mathrm{T}$ cell immunoglobulin and ITIM domain (TIGIT) and program death-1 (PD-1), and enhanced activation of $\mathrm{T}$ cells (Kinosada et al., 2017). Localization of HBZ protein was also reported in the cytoplasm of PBMCs of HAM/TSP patients (Baratella et al., 2017). Interestingly, $\mathrm{HBZ}$ protein is almost exclusively in $\mathrm{CD}^{+}{ }^{+} \mathrm{T}$ cells irrespective of co-expression of CD25 (Baratella et al., 2017). Thus, HBZ expression may be compartmentalized or cooperate with Tax expression in $\mathrm{HTLV}$-1-infected $\mathrm{CD}^{+} \mathrm{T}$ cells of HAM/TSP patients and may allow the virus to evade the host immune system. These findings of HBZ might shed light on a new molecular basis for a role of $\mathrm{HBZ}$ in the pathogenesis of HAM/TSP.

\section{Inflammation by HBZ}

As HBZ closely cooperates with Tax in many molecular mechanisms (Matsuoka and Jeang, 2011), opposing functions between HBZ and Tax have been also demonstrated in both in vitro and in vivo studies. HBZ enhanced TGF$\beta$ signaling and FoxP3 expression to induce Tregs from naïve $\mathrm{CD}^{+} \mathrm{T}$ cells while Tax reduced TGF- $\beta$ signaling and FoxP3 expression in $\mathrm{CD}^{+} \mathrm{T}$ cells (Grant et al., 2008; Zhao et al., 2011). HBZ suppresses the IFN- $\gamma$ gene transcription through inhibition of AP-1 and NFAT while Tax activates the IFN- $\gamma$ gene promoter (Sugata et al., 2012). Interestingly, HBZ transgenic (HBZ-Tg) mice develop both T-cell lymphomas and chronic inflammation in lung and skin (Satou et al., 2011). Currently, there is no report that HBZ-Tg mice develop inflammatory neurologic diseases and it remains unknown how tissue specificity of HTLV-1associated inflammatory diseases is determined, but similar immunological features with HAM/TSP patients have been demonstrated in HBZ-Tg mice. HBZ-Tg mice has been reported to show the increased effector/memory $\mathrm{CD}^{+} \mathrm{T}$ cells while effector/memory $\mathrm{CD}^{+} \mathrm{T}$ cells with high Tax-expression have been exhibited in HAM/TSP patients (Hanon et al., 2001; Satou et al., 2011). Further studies have demonstrated that Tregs of HBZ-Tg mice tend to lose expression of FoxP3 and Helios, leading to increased IFN- $\gamma$-expressing proinflammatory cells, associated with enhanced cell adhesion and migration of $\mathrm{CD}^{+} \mathrm{T}$ cells of HBZ-Tg mice (Yamamoto-Taguchi et al., 2013). Importantly, decreased Helios expression and enhanced cell adhesion molecules observed in HBZ-Tg mice were also detected in $\mathrm{CD}^{+}{ }^{+} \mathrm{T}$ cells of HAM/TSP patients (YamamotoTaguchi et al., 2013). In addition, the conserved non-coding sequence 2 region of the Foxp3 gene was hypermethylated in Tregs of HBZ-Tg mice, which is a characteristic of induced Tregs (Yamamoto-Taguchi et al., 2013). HAM/TSP patients also showed decreased demethylation of the Foxp3 gene in $\mathrm{CD} 4{ }^{+} \mathrm{CD} 25^{+} \mathrm{T}$ cells, compared to NDs, which correlated with the decreased suppressive capacity of $\mathrm{CD} 4^{+} \mathrm{CD} 25^{+} \mathrm{T}$ cells in HAM/TSP patients (Anderson et al., 2014). These results suggested that $\mathrm{HBZ}$ may be able to convert into the proinflammatory phenotype of HBZ-expressing $\mathrm{T}$ cells, suggesting that HBZ plays an important role in the disease process of HAM/TSP. 


\section{IMMUNE RESPONSE AGAINST TAX AND HBZ IN HAM/TSP}

\section{Tax-Specific Immune Responses}

Tax is an immunodominant antigen recognized by HTLV-1specific cytotoxic CD8 ${ }^{+} \mathrm{T}$ cells (CTLs) (Jacobson et al., 1990). $\mathrm{CD}^{+} \mathrm{T}$ cells play a crucial role in immunity against HTLV1 through their ability to secrete various factors that suppress viral replication and kill infected target cells in HTLV-1-infected subjects (Hanon et al., 2000b; Vine et al., 2004). However, in HAM/TSP patients, the frequency of HTLV-1 Tax-specific $\mathrm{CD}^{+} \mathrm{T}$ cells were even higher in CSF than in peripheral blood and were correlated with HTLV-1 PVL (Greten et al., 1998; Kubota et al., 1998; Nagai et al., 2001b). A recent study demonstrated that a more atrophic spinal cord in HAM/TSP was associated with higher percentage of inflammatory $\mathrm{CD}^{+}$ T cells and HTLV-1 PVL in CSF of HAM/TSP patients (Azodi et al., 2017). Moreover, it has been demonstrated that HTLV-1 Tax-specific $\mathrm{CD}^{+}{ }^{+} \mathrm{T}$ cells as well as $\mathrm{CD} 4^{+} \mathrm{T}$ cells expressing HTLV-1 proteins were detected in the parenchyma of the spinal cords, suggesting that the interaction between HTLV-1specific CTLs and HTLV-1-infected $\mathrm{CD} 4^{+} \mathrm{T}$ cells may cause bystander damages to resident cells in the CNS (Matsuura et al., 2015).

While virus-specific antibodies play an important role in the control of viral infections in the CNS, intrathecal antibody synthesis appear to be associated with both protective and pathogenic function in chronic infection and immunemediated diseases of the CNS. Intrathecal antibody synthesis against HTLV-1 has been also confirmed by the presence of HTLV-1-specific antibodies and oligoclonal IgG band in CSF of HAM/TSP patients (Gessain et al., 1988; Grimaldi et al., 1988; Link et al., 1989). Intrathecal antibody response to HTLV-1 inversely correlates with higher PVL and a worse prognostic outcome (Puccioni-Sohler et al., 1999). Moreover, antibodies against two HTLV-1 viral products, Tax and Gag p24, have been reported to cross-react with host antigens, heterogeneous ribonucleoprotein A1 (hnRNP A1) and peroxiredoxin-1 (PrX-1), respectively, suggesting that molecular mimicry may play a role in the pathogenesis of HAM/TSP, suggesting a role for molecular mimicry between an infectious agent and the CNS (Levin et al., 2002; Lee et al., 2008). Therefore, HTLV-1 Tax specific immune responses might be immunopathogenic, rather than protective, in HAM/TSP patients, due to high cytotoxicity, the production of inflammatory cytokines such as IFN- $\gamma$ and TNF- $\alpha$, associate with damage to the CNS.

\section{HBZ-Specific Immune Responses}

HBZ is also an immunogenic protein recognized by HBZ-specific CTL clones (Suemori et al., 2009; Macnamara et al., 2010). HBZspecific $\mathrm{CD}^{+} \mathrm{T}$ cells are detected in $\mathrm{AC}$ and HAM/TSP patients, and HBZ-specific CTL clones were able to lyse naturally infected cells isolated from AC and HAM/TSP patients, but not ATL patients (Suemori et al., 2009; Macnamara et al., 2010). However, the binding affinity of HBZ peptides to HLA class I molecules was found to be significantly weaker than that of peptides from Tax, and the frequency of HBZ-specific $\mathrm{CD} 8^{+} \mathrm{T}$ cells was very low in peripheral blood (Macnamara et al., 2010; Hilburn et al., 2011).

Antibody response against HBZ was detected in serum/plasma of HTLV-1-infected subjects, but the frequency of the subjects with anti-HBZ antibody was about $10-16 \%$ in ACs, ATL, and HAM/TSP patients and did not discriminate between clinical status (Enose-Akahata et al., 2013; Shiohama et al., 2016). In addition, antibody responses against $\mathrm{HBZ}$ was detectable in the CSF of HAM/TSP patients, but was not dramatically elevated, suggesting that HBZ-specific antibody is not intrathecally synthesized (Enose-Akahata et al., 2013).

It has been suggested that the low frequency and affinity of HBZ-specific immune responses may be consequence of the low expression and antigenicity of HBZ in infected cells. Unlike Tax-specific immune responses, it might be difficult to induce effective HBZ-specific immune responses in HAM/TSP patients although the $H B Z$ gene is constantly expressed while the tax gene is sporadically transcribed. Thus, HTLV-1-infected cells might be able to escape from host immune responses for long periods and result in persistence of HTLV-1 in infected individuals.

\section{CONCLUSION}

Both Tax and HBZ play critical roles in immune dysregulation in HAM/TSP. However, it is still unknown how expression of Tax and HBZ are regulated and how Tax and HBZ cooperate in naturally infected cells. Therapies that control the expression of HTLV-1 gene products might be effective in preventing the development of HAM/TSP. In addition, effective regulation or induction of HTLV-1 specific immune responses might improve the prognosis of patients with this disorder. Further studies will be necessary to identify the mechanism by which HTLV-1 gene products or other factors including HTLV-1specific immune responses contribute to the pathogenesis of HAM/TSP.

\section{AUTHOR CONTRIBUTIONS}

YE-A contributed to paper writing. AV contributed to discussion. SJ supervised and contributed to discussion and writing.

\section{ACKNOWLEDGMENT}

This research was supported by the Intramural Research Program of the NIH, NINDS. 


\section{REFERENCES}

Afonso, P. V., Ozden, S., Cumont, M. C., Seilhean, D., Cartier, L., Rezaie, P., et al. (2008). Alteration of blood-brain barrier integrity by retroviral infection. PLOS Pathog. 4:e1000205. doi: 10.1371/journal.ppat.1000205

Afonso, P. V., Ozden, S., Prevost, M. C., Schmitt, C., Seilhean, D., Weksler, B., et al. (2007). Human blood-brain barrier disruption by retroviral-infected lymphocytes: role of myosin light chain kinase in endothelial tight-junction disorganization. J. Immunol. 179, 2576-2583. doi: 10.4049/jimmunol.179.4. 2576

Ahuja, J., Kampani, K., Datta, S., Wigdahl, B., Flaig, K. E., and Jain, P. (2006). Use of human antigen presenting cell gene array profiling to examine the effect of human T-cell leukemia virus type 1 Tax on primary human dendritic cells. J. Neurovirol. 12, 47-59. doi: 10.1080/13550280600614981

Anderson, M. R., Enose-Akahata, Y., Massoud, R., Ngouth, N., Tanaka, Y., Oh, U., et al. (2014). Epigenetic modification of the FoxP3 TSDR in HAM/TSP decreases the functional suppression of Tregs. J. Neuroimmune Pharmacol. 9, 522-532. doi: 10.1007/s11481-014-9547-Z

Anderson, M. R., Kashanchi, F., and Jacobson, S. (2016). Exosomes in viral disease. Neurotherapeutics 13, 535-546. doi: 10.1007/s13311-016-0450-6

Araya, N., Sato, T., Ando, H., Tomaru, U., Yoshida, M., Coler-Reilly, A., et al. (2014). HTLV-1 induces a Th1-like state in CD4+CCR4+ T cells. J. Clin. Invest. 124, 3431-3442. doi: 10.1172/JCI75250

Arnold, J., Yamamoto, B., Li, M., Phipps, A. J., Younis, I., Lairmore, M. D., et al. (2006). Enhancement of infectivity and persistence in vivo by HBZ, a natural antisense coded protein of HTLV-1. Blood 107, 3976-3982. doi: 10.1182/blood2005-11-4551

Arnold, J., Zimmerman, B., Li, M., Lairmore, M. D., and Green, P. L. (2008). Human T-cell leukemia virus type-1 antisense-encoded gene, Hbz, promotes T-lymphocyte proliferation. Blood 112, 3788-3797. doi: 10.1182/blood-200804- 154286

Aye, M. M., Matsuoka, E., Moritoyo, T., Umehara, F., Suehara, M., Hokezu, Y., et al. (2000). Histopathological analysis of four autopsy cases of HTLVI-associated myelopathy/tropical spastic paraparesis: inflammatory changes occur simultaneously in the entire central nervous system. Acta Neuropathol. 100, 245-252. doi: 10.1007/s004019900170

Azimi, N., Brown, K., Bamford, R. N., Tagaya, Y., Siebenlist, U., and Waldmann, T. A. (1998). Human T cell lymphotropic virus type I Tax protein trans-activates interleukin 15 gene transcription through an NF-kappa $\beta$ site. Proc. Natl. Acad. Sci. U.S.A. 95, 2452-2457. doi: 10.1073/pnas.95.5.2452

Azimi, N., Jacobson, S., Leist, T., and Waldmann, T. A. (1999). Involvement of IL-15 in the pathogenesis of human T lymphotropic virus type I-associated myelopathy/tropical spastic paraparesis: implications for therapy with a monoclonal antibody directed to the IL-2/15R beta receptor. J. Immunol. 163, 4064-4072.

Azimi, N., Nagai, M., Jacobson, S., and Waldmann, T. A. (2001). IL-15 plays a major role in the persistence of Tax-specific CD8 cells in HAM/TSP patients. Proc. Natl. Acad. Sci. U.S.A. 98, 14559-14564. doi: 10.1073/pnas.251540598

Azodi, S., Nair, G., Enose-Akahata, Y., Charlip, E., Vellucci, A., Cortese, I., et al. (2017). Imaging spinal cord atrophy in progressive myelopathies: HTLV-Iassociated neurological disease (HAM/TSP) and multiple sclerosis (MS). Ann. Neurol. 82, 719-728. doi: 10.1002/ana.25072

Banerjee, P., Rochford, R., Antel, J., Canute, G., Wrzesinski, S., Sieburg, M., et al. (2007). Proinflammatory cytokine gene induction by human T-cell leukemia virus type 1 (HTLV-1) and HTLV-2 Tax in primary human glial cells. J. Virol. 81, 1690-1700. doi: 10.1128/JVI.01513-06

Baratella, M., Forlani, G., Raval, G. U., Tedeschi, A., Gout, O., Gessain, A., et al. (2017). Cytoplasmic localization of HTLV-1 HBZ protein: a biomarker of HTLV-1-associated myelopathy/tropical spastic paraparesis (HAM/TSP). PLOS Negl. Trop. Dis. 11:e0005285. doi: 10.1371/journal.pntd.0005285

Billman, M. R., Rueda, D., and Bangham, C. R. M. (2017). Single-cell heterogeneity and cell-cycle-related viral gene bursts in the human leukaemia virus HTLV-1. Wellcome Open Res. 2:87. doi: 10.12688/wellcomeopenres.12469.1

Brunetto, G. S., Massoud, R., Leibovitch, E. C., Caruso, B., Johnson, K., Ohayon, J., et al. (2014). Digital droplet PCR (ddPCR) for the precise quantification of human T-lymphotropic virus 1 proviral loads in peripheral blood and cerebrospinal fluid of HAM/TSP patients and identification of viral mutations. J. Neurovirol. 20, 341-351. doi: 10.1007/s13365-014-0249-3
Cartier, L., and Ramirez, E. (2005). Presence of HTLV-I Tax protein in cerebrospinal fluid from HAM/TSP patients. Arch. Virol. 150, 743-753. doi: 10.1007/s00705-004-0443-3

Croft, M., So, T., Duan, W., and Soroosh, P. (2009). The significance of OX40 and OX40L to T-cell biology and immune disease. Immunol. Rev. 229, 173-191. doi: 10.1111/j.1600-065X.2009.00766.x

Cross, S. L., Feinberg, M. B., Wolf, J. B., Holbrook, N. J., Wong-Staal, F., and Leonard, W. J. (1987). Regulation of the human interleukin-2 receptor alpha chain promoter: activation of a nonfunctional promoter by the transactivator gene of HTLV-I. Cell 49, 47-56. doi: 10.1016/0092-8674(87)90754-9

Curis, C., Percher, F., Jeannin, P., Montange, T., Chevalier, S. A., Seilhean, D., et al. (2016). Human T-lymphotropic virus type 1-induced overexpression of activated leukocyte cell adhesion molecule (ALCAM) facilitates trafficking of infected lymphocytes through the blood-brain barrier. J. Virol. 90, 7303-7312. doi: 10.1128/JVI.00539-16

de The, G., and Bomford, R. (1993). An HTLV-I vaccine: Why, how, for whom? AIDS Res. Hum. Retroviruses 9, 381-386. doi: 10.1089/aid.1993. 9.381

Derse, D., Crise, B., Li, Y., Princler, G., Lum, N., Stewart, C., et al. (2007). Human T-cell leukemia virus type 1 integration target sites in the human genome: comparison with those of other retroviruses. J. Virol. 81, 6731-6741. doi: 10.1128/JVI.02752-06

Doi, K., Wu, X., Taniguchi, Y., Yasunaga, J., Satou, Y., Okayama, A., et al. (2005). Preferential selection of human T-cell leukemia virus type I provirus integration sites in leukemic versus carrier states. Blood 106, 1048-1053. doi: 10.1182/ blood-2004-11-4350

Enose-Akahata, Y., Abrams, A., Massoud, R., Bialuk, I., Johnson, K. R., Green, P. L., et al. (2013). Humoral immune response to HTLV-1 basic leucine zipper factor (HBZ) in HTLV-1-infected individuals. Retrovirology 10:19. doi: 10.1186/17424690-10-19

Enose-Akahata, Y., Oh, U., Grant, C., and Jacobson, S. (2008). Retrovirally induced CTL degranulation mediated by IL-15 expression and infection of mononuclear phagocytes in patients with HTLV-I-associated neurologic disease. Blood 112, 2400-2410. doi: 10.1182/blood-2008-02-138529

Gaudray, G., Gachon, F., Basbous, J., Biard-Piechaczyk, M., Devaux, C., and Mesnard, J. M. (2002). The complementary strand of the human T-cell leukemia virus type 1 RNA genome encodes a bZIP transcription factor that downregulates viral transcription. J. Virol. 76, 12813-12822. doi: 10.1128/JVI.76.24. 12813-12822.2002

Gessain, A., Barin, F., Vernant, J. C., Gout, O., Maurs, L., Calender, A., et al. (1985). Antibodies to human T-lymphotropic virus type-I in patients with tropical spastic paraparesis. Lancet 2, 407-410. doi: 10.1016/S0140-6736(85)92734-5

Gessain, A., and Cassar, O. (2012). Epidemiological aspects and world distribution of HTLV-1 infection. Front. Microbiol. 3:388. doi: 10.3389/fmicb.2012.00388

Gessain, A., Caudie, C., Gout, O., Vernant, J. C., Maurs, L., Giordano, C., et al. (1988). Intrathecal synthesis of antibodies to human T lymphotropic virus type I and the presence of IgG oligoclonal bands in the cerebrospinal fluid of patients with endemic tropical spastic paraparesis. J. Infect. Dis. 157, 1226-1234. doi: 10.1093/infdis/157.6.1226

Gillet, N. A., Malani, N., Melamed, A., Gormley, N., Carter, R., Bentley, D., et al. (2011). The host genomic environment of the provirus determines the abundance of HTLV-1-infected T-cell clones. Blood 117, 3113-3122. doi: 10.1182/blood-2010-10-312926

Grant, C., Oh, U., Yao, K., Yamano, Y., and Jacobson, S. (2008). Dysregulation of TGF-beta signaling and regulatory and effector T-cell function in virus-induced neuroinflammatory disease. Blood 111, 5601-5609. doi: 10.1182/blood-200711- 123430

Greten, T. F., Slansky, J. E., Kubota, R., Soldan, S. S., Jaffee, E. M., Leist, T. P., et al. (1998). Direct visualization of antigen-specific T cells: HTLV-1 Tax1119- specific $\mathrm{CD}^{+} \mathrm{T}$ cells are activated in peripheral blood and accumulate in cerebrospinal fluid from HAM/TSP patients. Proc. Natl. Acad. Sci. U.S.A. 95, 7568-7573. doi: 10.1073/pnas.95.13.7568

Grimaldi, L. M., Roos, R. P., Devare, S. G., Casey, J. M., Maruo, Y., Hamada, T., et al. (1988). HTLV-I-associated myelopathy: oligoclonal immunoglobulin G bands contain anti-HTLV-I p24 antibody. Ann. Neurol. 24, 727-731. doi: 10.1002/ana.410240606

Hanon, E., Asquith, R. E., Taylor, G. P., Tanaka, Y., Weber, J. N., and Bangham, C. R. (2000a). High frequency of viral protein expression in human $\mathrm{T}$ cell 
lymphotropic virus type 1-infected peripheral blood mononuclear cells. AIDS Res. Hum. Retroviruses 16, 1711-1715. doi: 10.1089/08892220050193191

Hanon, E., Goon, P., Taylor, G. P., Hasegawa, H., Tanaka, Y., Weber, J. N., et al. (2001). High production of interferon gamma but not interleukin-2 by human T-lymphotropic virus type I-infected peripheral blood mononuclear cells. Blood 98, 721-726. doi: 10.1182/blood.V98.3.721

Hanon, E., Hall, S., Taylor, G. P., Saito, M., Davis, R., Tanaka, Y., et al. (2000b). Abundant tax protein expression in CD4+ T cells infected with human T-cell lymphotropic virus type I (HTLV-I) is prevented by cytotoxic T lymphocytes. Blood 95, 1386-1392.

Hanon, E., Stinchcombe, J. C., Saito, M., Asquith, B. E., Taylor, G. P., Tanaka, Y., et al. (2000c). Fratricide among $\mathrm{CD}^{+} \mathrm{T}^{\mathrm{T}}$ lymphocytes naturally infected with human T cell lymphotropic virus type I. Immunity 13, 657-664.

Higashimura, N., Takasawa, N., Tanaka, Y., Nakamura, M., and Sugamura, K. (1996). Induction of OX40, a receptor of gp34, on T cells by trans-acting transcriptional activator, Tax, of human T-cell leukemia virus type I. Jpn. J. Cancer Res. 87, 227-231. doi: 10.1111/j.1349-7006.1996.tb00210.x

Hilburn, S., Rowan, A., Demontis, M. A., MacNamara, A., Asquith, B., Bangham, C. R., et al. (2011). In vivo expression of human T-lymphotropic virus type 1 basic leucine-zipper protein generates specific $\mathrm{CD} 8^{+}$and $\mathrm{CD} 4^{+} \mathrm{T}$-lymphocyte responses that correlate with clinical outcome. J. Infect. Dis. 203, 529-536. doi: 10.1093/infdis/jiq078

Hivin, P., Frederic, M., Arpin-Andre, C., Basbous, J., Gay, B., Thebault, S., et al. (2005). Nuclear localization of HTLV-I bZIP factor (HBZ) is mediated by three distinct motifs. J. Cell Sci. 118(Pt 7), 1355-1362. doi: 10.1242/jcs.01727

Hoffman, P. M., Dhib-Jalbut, S., Mikovits, J. A., Robbins, D. S., Wolf, A. L., Bergey, G. K., et al. (1992). Human T-cell leukemia virus type I infection of monocytes and microglial cells in primary human cultures. Proc. Natl. Acad. Sci. U.S.A. 89, 11784-11788. doi: 10.1073/pnas.89.24.11784

Iwasaki, Y. (1990). Pathology of chronic myelopathy associated with HTLV-I infection (HAM/TSP). J. Neurol. Sci. 96, 103-123. doi: 10.1016/0022-510X(90) 90060-Z

Jacobson, S., Shida, H., McFarlin, D. E., Fauci, A. S., and Koenig, S. (1990). Circulating $\mathrm{CD}^{+}$cytotoxic $\mathrm{T}$ lymphocytes specific for HTLV-I pX in patients with HTLV-I associated neurological disease. Nature 348, 245-248. doi: $10.1038 / 348245 \mathrm{a} 0$

Jaworski, E., Narayanan, A., Van Duyne, R., Shabbeer-Meyering, S., Iordanskiy, S., Saifuddin, M., et al. (2014). Human T-lymphotropic virus type 1-infected cells secrete exosomes that contain Tax protein. J. Biol. Chem. 289, 22284-22305. doi: 10.1074/jbc.M114.549659

Kinosada, H., Yasunaga, J. I., Shimura, K., Miyazato, P., Onishi, C., Iyoda, T., et al. (2017). HTLV-1 bZIP factor enhances T-cell proliferation by impeding the suppressive signaling of co-inhibitory receptors. PLOS Pathog. 13:e1006120. doi: 10.1371/journal.ppat.1006120

Koralnik, I. J., Lemp, J. F. Jr., Gallo, R. C., and Franchini, G. (1992). In vitro infection of human macrophages by human T-cell leukemia/lymphotropic virus type I (HTLV-I). AIDS Res. Hum. Retroviruses 8, 1845-1849. doi: 10.1089/aid. 1992.8.1845

Koyanagi, Y., Itoyama, Y., Nakamura, N., Takamatsu, K., Kira, J., Iwamasa, T., et al. (1993). In vivo infection of human T-cell leukemia virus type I in non-T cells. Virology 196, 25-33. doi: 10.1006/viro.1993.1451

Kubota, R., Kawanishi, T., Matsubara, H., Manns, A., and Jacobson, S. (1998). Demonstration of human $\mathrm{T}$ lymphotropic virus type I (HTLV-I) taxspecific $\mathrm{CD} 8^{+}$lymphocytes directly in peripheral blood of HTLV-I-associated myelopathy/tropical spastic paraparesis patients by intracellular cytokine detection. J. Immunol. 161, 482-488.

Leal, F. E., Ndhlovu, L. C., Hasenkrug, A. M., Bruno, F. R., Carvalho, K. I., WynnWilliams, H., et al. (2013). Expansion in $\mathrm{CD} 39^{+} \mathrm{CD} 4^{+}$immunoregulatory $\mathrm{T}$ cells and rarity of Th17 cells in HTLV-1 infected patients is associated with neurological complications. PLOS Negl. Trop. Dis. 7:e2028. doi: 10.1371/ journal.pntd.0002028

Lee, S., Shin, Y., Marler, J., and Levin, M. C. (2008). Post-translational glycosylation of target proteins implicate molecular mimicry in the pathogenesis of HTLV-1 associated neurological disease. J. Neuroimmunol. 204, 140-148. doi: 10.1016/j. jneuroim.2008.07.020

Lehky, T. J., Fox, C. H., Koenig, S., Levin, M. C., Flerlage, N., Izumo, S., et al. (1995). Detection of human T-lymphotropic virus type I (HTLV-I) tax RNA in the central nervous system of HTLV-I-associated myelopathy/tropical spastic paraparesis patients by in situ hybridization. Ann. Neurol. 37, 167-175. doi: 10.1002/ana.410370206

Levin, M. C., Lee, S. M., Kalume, F., Morcos, Y., Dohan, F. C. Jr., Hasty, K. A., et al. (2002). Autoimmunity due to molecular mimicry as a cause of neurological disease. Nat. Med. 8, 509-513. doi: 10.1038/nm0502-509

Link, H., Cruz, M., Gessain, A., Gout, O., de The, G., and Kam-Hansen, S. (1989). Chronic progressive myelopathy associated with HTLV-I: oligoclonal IgG and anti-HTLV-I IgG antibodies in cerebrospinal fluid and serum. Neurology 39, 1566-1572. doi: 10.1212/WNL.39.12.1566

Liu, W., Nair, G., Vuolo, L., Bakshi, A., Massoud, R., Reich, D. S., et al. (2014). In vivo imaging of spinal cord atrophy in neuroinflammatory diseases. Ann. Neurol. 76, 370-378. doi: 10.1002/ana.24213

Macnamara, A., Rowan, A., Hilburn, S., Kadolsky, U., Fujiwara, H., Suemori, K., et al. (2010). HLA class I binding of HBZ determines outcome in HTLV-1 infection. PLOS Pathog. 6:e1001117. doi: 10.1371/journal.ppat.1001117

Makino, M., Shimokubo, S., Wakamatsu, S. I., Izumo, S., and Baba, M. (1999). The role of human T-lymphotropic virus type 1 (HTLV-1)-infected dendritic cells in the development of HTLV-1-associated myelopathy/tropical spastic paraparesis. J. Virol. 73, 4575-4581.

Maldonado, H., Ramirez, E., Utreras, E., Pando, M. E., Kettlun, A. M., Chiong, M., et al. (2011). Inhibition of cyclin-dependent kinase 5 but not of glycogen synthase kinase 3-beta prevents neurite retraction and tau hyperphosphorylation caused by secretable products of human T-cell leukemia virus type I-infected lymphocytes. J. Neurosci. Res. 89, 1489-1498. doi: 10.1002/ jnr.22678

Manivannan, K., Rowan, A. G., Tanaka, Y., Taylor, G. P., and Bangham, C. R. (2016). CADM1/TSLC1 identifies HTLV-1-infected cells and determines their susceptibility to CTL-mediated lysis. PLOS Pathog. 12:e1005560. doi: 10.1371/ journal.ppat. 1005560

Mariner, J. M., Lantz, V., Waldmann, T. A., and Azimi, N. (2001). Human T cell lymphotropic virus type I Tax activates IL-15R alpha gene expression through an NF-kappa B site. J. Immunol. 166, 2602-2609. doi: 10.4049/jimmunol.166.4. 2602

Matsuoka, M., and Jeang, K. T. (2007). Human T-cell leukaemia virus type 1 (HTLV-1) infectivity and cellular transformation. Nat. Rev. Cancer 7, 270-280. doi: $10.1038 / \mathrm{nrc} 2111$

Matsuoka, M., and Jeang, K. T. (2011). Human T-cell leukemia virus type 1 (HTLV-1) and leukemic transformation: viral infectivity, Tax, HBZ and therapy. Oncogene 30, 1379-1389. doi: 10.1038/onc.2010.537

Matsuura, E., Kubota, R., Tanaka, Y., Takashima, H., and Izumo, S. (2015). Visualization of HTLV-1-specific cytotoxic T lymphocytes in the spinal cords of patients with HTLV-1-associated myelopathy/tropical spastic paraparesis. J. Neuropathol. Exp. Neurol. 74, 2-14. doi: 10.1097/NEN.0000000000000141

Matsuura, E., Yamano, Y., and Jacobson, S. (2010). Neuroimmunity of HTLV-I infection. J. Neuroimmune Pharmacol. 5, 310-325. doi: 10.1007/s11481-0109216-9

Medina, F., Quintremil, S., Alberti, C., Barriga, A., Cartier, L., Puente, J., et al. (2014). Tax posttranslational modifications and interaction with calreticulin in MT-2 cells and human peripheral blood mononuclear cells of human T cell lymphotropic virus type-I-associated myelopathy/tropical spastic paraparesis patients. AIDS Res. Hum. Retroviruses 30, 370-379. doi: 10.1089/AID.2013. 0036

Meekings, K. N., Leipzig, J., Bushman, F. D., Taylor, G. P., and Bangham, C. R. (2008). HTLV-1 integration into transcriptionally active genomic regions is associated with proviral expression and with HAM/TSP. PLOS Pathog. 4:e1000027. doi: 10.1371/journal.ppat.1000027

Melamed, A., Laydon, D. J., Gillet, N. A., Tanaka, Y., Taylor, G. P., and Bangham, C. R. (2013). Genome-wide determinants of proviral targeting, clonal abundance and expression in natural HTLV-1 infection. PLOS Pathog. 9:e1003271. doi: 10.1371/journal.ppat.1003271

Mendez, E., Kawanishi, T., Clemens, K., Siomi, H., Soldan, S. S., Calabresi, P., et al. (1997). Astrocyte-specific expression of human T-cell lymphotropic virus type 1 (HTLV-1) Tax: induction of tumor necrosis factor alpha and susceptibility to lysis by CD8 ${ }^{+}$HTLV-1-specific cytotoxic T cells. J. Virol. 71, 9143-9149.

Mizuguchi, M., Asao, H., Hara, T., Higuchi, M., Fujii, M., and Nakamura, M. (2009). Transcriptional activation of the interleukin-21 gene and its receptor gene by human T-cell leukemia virus type 1 Tax in human T-cells. J. Biol. Chem. 284, 25501-25511. doi: 10.1074/jbc.M109.010959 
Mori, N., Sato, H., Hayashibara, T., Senba, M., Hayashi, T., Yamada, Y., et al. (2002). Human T-cell leukemia virus type I Tax transactivates the matrix metalloproteinase-9 gene: potential role in mediating adult T-cell leukemia invasiveness. Blood 99, 1341-1349. doi: 10.1182/blood.V99.4.1341

Moritoyo, T., Izumo, S., Moritoyo, H., Tanaka, Y., Kiyomatsu, Y., Nagai, M., et al. (1999). Detection of human T-lymphotropic virus type I p40tax protein in cerebrospinal fluid cells from patients with human T-lymphotropic virus type I-associated myelopathy/tropical spastic paraparesis. J. Neurovirol. 5, 241-248. doi: 10.3109/13550289909015810

Nagai, M., Kubota, R., Greten, T. F., Schneck, J. P., Leist, T. P., and Jacobson, S. (2001a). Increased activated human T cell lymphotropic virus type I (HTLV-I) Tax11-19-specific memory and effector $\mathrm{CD}^{+}$cells in patients with HTLVI-associated myelopathy/tropical spastic paraparesis: correlation with HTLV-I provirus load. J. Infect. Dis. 183, 197-205. doi: 10.1086/317932

Nagai, M., Usuku, K., Matsumoto, W., Kodama, D., Takenouchi, N., Moritoyo, T., et al. (1998). Analysis of HTLV-I proviral load in 202 HAM/TSP patients and 243 asymptomatic HTLV-I carriers: high proviral load strongly predisposes to HAM/TSP. J. Neurovirol. 4, 586-593. doi: 10.3109/13550289809114225

Nagai, M., Yamano, Y., Brennan, M. B., Mora, C. A., and Jacobson, S. (2001b). Increased HTLV-I proviral load and preferential expansion of HTLV-I Taxspecific $\mathrm{CD}^{+} \mathrm{T}$ cells in cerebrospinal fluid from patients with HAM/TSP. Ann. Neurol. 50, 807-812.

Nejmeddine, M., Negi, V. S., Mukherjee, S., Tanaka, Y., Orth, K., Taylor, G. P., et al. (2009). HTLV-1-Tax and ICAM-1 act on T-cell signal pathways to polarize the microtubule-organizing center at the virological synapse. Blood 114, 1016-1025. doi: 10.1182/blood-2008-03-136770

Oh, U., McCormick, M. J., Datta, D., Turner, R. V., Bobb, K., Monie, D. D., et al. (2011). Inhibition of immune activation by a novel nuclear factor-kappa B inhibitor in HTLV-I-associated neurologic disease. Blood 117, 3363-3369. doi: 10.1182/blood-2010-10-306571

Osame, M., Usuku, K., Izumo, S., Ijichi, N., Amitani, H., Igata, A., et al. (1986). HTLV-I associated myelopathy, a new clinical entity. Lancet 1, 1031-1032. doi: 10.1016/S0140-6736(86)91298-5

Poiesz, B. J., Ruscetti, F. W., Gazdar, A. F., Bunn, P. A., Minna, J. D., and Gallo, R. C. (1980). Detection and isolation of type C retrovirus particles from fresh and cultured lymphocytes of a patient with cutaneous T-cell lymphoma. Proc. Natl. Acad. Sci. U.S.A. 77, 7415-7419. doi: 10.1073/pnas.77.12.7415

Puccioni-Sohler, M., Rios, M., Bianco, C., Zhu, S. W., Oliveira, C., Novis, S. A., et al. (1999). An inverse correlation of HTLV-I viral load in CSF and intrathecal synthesis of HTLV-I antibodies in TSP/HAM. Neurology 53, 1335-1339. doi: 10.1212/WNL.53.6.1335

Puccioni-Sohler, M., Yamano, Y., Rios, M., Carvalho, S. M., Vasconcelos, C. C., Papais-Alvarenga, R., et al. (2007). Differentiation of HAM/TSP from patients with multiple sclerosis infected with HTLV-I. Neurology 68, 206-213. doi: 10.1212/01.wnl.0000251300.24540.c4

Rende, F., Cavallari, I., Corradin, A., Silic-Benussi, M., Toulza, F., Toffolo, G. M., et al. (2011). Kinetics and intracellular compartmentalization of HTLV-1 gene expression: nuclear retention of HBZ mRNAs. Blood 117, 4855-4859. doi: 10.1182/blood-2010-11-316463

Richardson, J. H., Edwards, A. J., Cruickshank, J. K., Rudge, P., and Dalgleish, A. G. (1990). In vivo cellular tropism of human T-cell leukemia virus type 1. J. Virol. 64, 5682-5687.

Saito, M., Matsuzaki, T., Satou, Y., Yasunaga, J., Saito, K., Arimura, K., et al. (2009). In vivo expression of the HBZ gene of HTLV-1 correlates with proviral load, inflammatory markers and disease severity in HTLV-1 associated myelopathy/tropical spastic paraparesis (HAM/TSP). Retrovirology 6:19. doi: 10.1186/1742-4690-6-19

Saito, M., Tanaka, R., Arishima, S., Matsuzaki, T., Ishihara, S., Tokashiki, T., et al. (2013). Increased expression of OX40 is associated with progressive disease in patients with HTLV-1-associated myelopathy/tropical spastic paraparesis. Retrovirology 10:51. doi: 10.1186/1742-4690-10-51

Sakaguchi, S., Sakaguchi, N., Shimizu, J., Yamazaki, S., Sakihama, T., Itoh, M., et al. (2001). Immunologic tolerance maintained by $\mathrm{CD} 25^{+} \mathrm{CD} 4^{+}$regulatory T cells: their common role in controlling autoimmunity, tumor immunity, and transplantation tolerance. Immunol. Rev. 182, 18-32. doi: 10.1034/j.1600-065X. 2001.1820102.x

Satou, Y., Miyazato, P., Ishihara, K., Yaguchi, H., Melamed, A., Miura, M., et al. (2016). The retrovirus HTLV-1 inserts an ectopic CTCF-binding site into the human genome. Proc. Natl. Acad. Sci. U.S.A. 113, 3054-3059. doi: 10.1073/pnas. 1423199113

Satou, Y., Yasunaga, J., Yoshida, M., and Matsuoka, M. (2006). HTLV-I basic leucine zipper factor gene mRNA supports proliferation of adult $\mathrm{T}$ cell leukemia cells. Proc. Natl. Acad. Sci. U.S.A. 103, 720-725. doi: 10.1073/pnas.0507631103

Satou, Y., Yasunaga, J., Zhao, T., Yoshida, M., Miyazato, P., Takai, K., et al. (2011). HTLV-1 bZIP factor induces T-cell lymphoma and systemic inflammation in vivo. PLOS Pathog. 7:e1001274. doi: 10.1371/journal.ppat.1001274

Shiohama, Y., Naito, T., Matsuzaki, T., Tanaka, R., Tomoyose, T., Takashima, H., et al. (2016). Absolute quantification of HTLV-1 basic leucine zipper factor (HBZ) protein and its plasma antibody in HTLV-1 infected individuals with different clinical status. Retrovirology 13:29. doi: 10.1186/s12977-016-0263-z

Siekevitz, M., Feinberg, M. B., Holbrook, N., Wong-Staal, F., and Greene, W. C. (1987). Activation of interleukin 2 and interleukin 2 receptor (Tac) promoter expression by the trans-activator (tat) gene product of human T-cell leukemia virus, type I. Proc. Natl. Acad. Sci. U.S.A. 84, 5389-5393. doi: 10.1073/pnas.84. 15.5389

Suemori, K., Fujiwara, H., Ochi, T., Ogawa, T., Matsuoka, M., Matsumoto, T., et al. (2009). HBZ is an immunogenic protein, but not a target antigen for human T-cell leukemia virus type 1-specific cytotoxic T lymphocytes. J. Gen. Virol. 90(Pt 8), 1806-1811. doi: 10.1099/vir.0.010199-0

Sugata, K., Satou, Y., Yasunaga, J., Hara, H., Ohshima, K., Utsunomiya, A., et al. (2012). HTLV-1 bZIP factor impairs cell-mediated immunity by suppressing production of Th1 cytokines. Blood 119, 434-444. doi: 10.1182/blood-2011-05357459

Takeda, S., Maeda, M., Morikawa, S., Taniguchi, Y., Yasunaga, J., Nosaka, K., et al. (2004). Genetic and epigenetic inactivation of tax gene in adult T-cell leukemia cells. Int. J. Cancer 109, 559-567. doi: 10.1002/ijc.20007

Uchiyama, T. (1988). Adult T-cell leukemia. Blood Rev. 2, 232-238. doi: 10.1016/ 0268-960X(88)90012-4

Umehara, F., Izumo, S., Nakagawa, M., Ronquillo, A. T., Takahashi, K., Matsumuro, K., et al. (1993). Immunocytochemical analysis of the cellular infiltrate in the spinal cord lesions in HTLV-I-associated myelopathy. J. Neuropathol. Exp. Neurol. 52, 424-430. doi: 10.1097/00005072-19930700000010

Umehara, F., Okada, Y., Fujimoto, N., Abe, M., Izumo, S., and Osame, M. (1998). Expression of matrix metalloproteinases and tissue inhibitors of metalloproteinases in HTLV-I-associated myelopathy. J. Neuropathol. Exp. Neurol. 57, 839-849. doi: 10.1097/00005072-199809000-00005

Usui, T., Yanagihara, K., Tsukasaki, K., Murata, K., Hasegawa, H., Yamada, Y., et al. (2008). Characteristic expression of HTLV-1 basic zipper factor (HBZ) transcripts in HTLV-1 provirus-positive cells. Retrovirology 5:34. doi: 10.1186/ 1742-4690-5-34

Valentin, H., Lemasson, I., Hamaia, S., Casse, H., Konig, S., Devaux, C., et al. (1997). Transcriptional activation of the vascular cell adhesion molecule-1 gene in $\mathrm{T}$ lymphocytes expressing human T-cell leukemia virus type 1 Tax protein. J. Virol. $71,8522-8530$.

Vine, A. M., Heaps, A. G., Kaftantzi, L., Mosley, A., Asquith, B., Witkover, A., et al. (2004). The role of CTLs in persistent viral infection: cytolytic gene expression in $\mathrm{CD}^{+}$lymphocytes distinguishes between individuals with a high or low proviral load of human T cell lymphotropic virus type 1. J. Immunol. 173, 5121-5129. doi: 10.4049/jimmunol.173.8.5121

Waldmann, T. A. (2015). The shared and contrasting roles of IL2 and IL15 in the life and death of normal and neoplastic lymphocytes: implications for cancer therapy. Cancer Immunol. Res. 3, 219-227. doi: 10.1158/2326-6066.CIR-150009

Wan, Y. Y., and Flavell, R. A. (2007). 'Yin-Yang' functions of transforming growth factor-beta and $\mathrm{T}$ regulatory cells in immune regulation. Immunol. Rev. 220, 199-213. doi: 10.1111/j.1600-065X.2007.00565.X

Yamamoto-Taguchi, N., Satou, Y., Miyazato, P., Ohshima, K., Nakagawa, M., Katagiri, K., et al. (2013). HTLV-1 bZIP factor induces inflammation through labile Foxp3 expression. PLOS Pathog. 9:e1003630. doi: 10.1371/journal.ppat. 1003630

Yamano, Y., Araya, N., Sato, T., Utsunomiya, A., Azakami, K., Hasegawa, D., et al. (2009). Abnormally high levels of virus-infected IFN-gamma ${ }^{+} \mathrm{CCR}^{+} \mathrm{CD}_{4}{ }^{+} \mathrm{CD} 25^{+} \mathrm{T}$ cells in a retrovirus-associated neuroinflammatory disorder. PLOS ONE 4:e6517. doi: 10.1371/journal. pone. 0006517 
Yamano, Y., Cohen, C. J., Takenouchi, N., Yao, K., Tomaru, U., Li, H. C., et al. (2004). Increased expression of human T lymphocyte virus type I (HTLV-I) Tax11-19 peptide-human histocompatibility leukocyte antigen A*201 complexes on $\mathrm{CD}^{+} \mathrm{CD}^{+} 5^{+} \mathrm{T}$ Cells detected by peptide-specific, major histocompatibility complex-restricted antibodies in patients with HTLV-Iassociated neurologic disease. J. Exp. Med. 199, 1367-1377. doi: 10.1084/jem. 20032042

Yamano, Y., Nagai, M., Brennan, M., Mora, C. A., Soldan, S. S., Tomaru, U., et al. (2002). Correlation of human T-cell lymphotropic virus type 1 (HTLV-1) mRNA with proviral DNA load, virus-specific $\mathrm{CD}^{+} \mathrm{T}$ cells, and disease severity in HTLV-1-associated myelopathy (HAM/TSP). Blood 99, 88-94. doi: 10.1182/blood.V99.1.88

Yamano, Y., and Sato, T. (2012). Clinical pathophysiology of human T-lymphotropic virus-type 1-associated myelopathy/tropical spastic paraparesis. Front. Microbiol. 3:389. doi: 10.3389/fmicb.2012.00389

Yamano, Y., Takenouchi, N., Li, H. C., Tomaru, U., Yao, K., Grant, C. W., et al. (2005). Virus-induced dysfunction of $\mathrm{CD}^{+} \mathrm{CD} 25^{+} \mathrm{T}$ cells in patients with HTLV-I-associated neuroimmunological disease. J. Clin. Invest. 115, 1361-1368. doi: 10.1172/JCI23913

Zhao, T., Satou, Y., Sugata, K., Miyazato, P., Green, P. L., Imamura, T., et al. (2011). HTLV-1 bZIP factor enhances TGF-beta signaling through p300 coactivator. Blood 118, 1865-1876. doi: 10.1182/blood-2010-12-32 6199

Conflict of Interest Statement: The authors declare that the research was conducted in the absence of any commercial or financial relationships that could be construed as a potential conflict of interest.

Copyright (c) 2017 Enose-Akahata, Vellucci and Jacobson. This is an open-access article distributed under the terms of the Creative Commons Attribution License (CC BY). The use, distribution or reproduction in other forums is permitted, provided the original author(s) or licensor are credited and that the original publication in this journal is cited, in accordance with accepted academic practice. No use, distribution or reproduction is permitted which does not comply with these terms. 